Please do not remove this page

RMIT

UNIVERSITY

\title{
Cash for care under the NDIS: Shaping care workers' working conditions?
}

Macdonald, Fiona; Charlesworth, Sara

https://researchrepository.rmit.edu.au/esploro/outputs/9921858882901341/filesAndLinks?institution=61RMIT_INST\&index=null

Macdonald, F., \& Charlesworth, S. (2016). Cash for care under the NDIS: Shaping care workers' working conditions? Journal of Industrial Relations, 58(5), 627-646. https://doi.org/10.1177/0022185615623083

Document Version: Accepted Manuscript

Published Version: https://doi.org/10.1177/0022185615623083

Repository homepage: https://researchrepository.rmit.edu.au

(c) Australian Labour and Employment Relations Association

Downloaded On 2023/04/26 10:58:47 +1000 
Pre-print version: Accepted for publication

Journal of Industrial Relations (2016)

\section{Cash-for-care under the NDIS: Shaping care workers' working conditions?}

\section{Fiona Macdonald and Sara Charlesworth}

The Australian National Disability Insurance Scheme (NDIS) introduces a national cash-for-care model for disability support and care. The NDIS has been hailed as a significant advance in social care provision for people with disability, bringing both additional funding and choice and control. However, little attention has been paid to how the shift to a cash-for-care system will impact on the working conditions of disability support workers. The international literature suggests three main factors shape better or poorer employment outcomes for workers in cashfor-care schemes: the extent to which cost containment underpins scheme design; the regulation and monitoring of care delivery; and the regulation of care employment. In this paper we explore these factors through an analysis of the planning, design and initial implementation of the NDIS and make a preliminary assessment of how the new scheme might shape care workers' employment conditions.

Key words: cash-for-care, National Disability Insurance Scheme, working conditions, care delivery, employment regulation. 
Across advanced economies governments are adopting commodified care or 'cash-forcare' schemes for long-term care (Columbo et al., 2011; Ungerson \& Yeandle, 2007a). While these schemes vary in design they all involve the allocation of funding to individual care users or family carers to purchase care and support services to meet their particular needs and preferences, rather than having to access standardised services (Colombo et al., 2011, p.50). In Australia, the National Disability Insurance Scheme (NDIS) introduces a national cash-for-care model for disability care and support.

Cash-for-care schemes have been in place in social care systems across Europe and North America for some time (Colombo et al., 2011; Ungerson, 1997). While recent comparative studies have paid attention to how these schemes might shape care labour markets and impact on care jobs (Da Roit \& Le Bihan, 2010; Ungerson \& Yeandle, 2007a) there has been relatively little research into their impacts on care workers' employment arrangements and working conditions.

The nature of changes to the organisation of care and support work in cash-for-care systems suggest these schemes present significant new challenges for traditional regulatory approaches to managing employment risks for the low-paid, mainly female 
care and support workforce. Cash-for-care schemes shift the location of care work from solely service provider organisations to more diverse settings, including private households (Da Roit \& Le Bihan, 2010; Ungerson \& Yeandle, 2007a). They introduce new demands for flexibility, for very short hours' work and for travel between multiple work locations (Christensen, 2012; Yeandle \& Stiell, 2007). For example, prior to the introduction of the NDIS, disability support workers in Australia have mostly been employed in organisations such as specialist day centres where staffing is managed for groups of workers around regular shifts in a single location. The NDIS shifts the focus to support for the individual at home and in the community, with work organised round individual units of care. In some cash-for-care schemes, including the NDIS, care workers can be directly employed by or contracted to individual care users (Commonwealth of Australia, 2013).

Working arrangements under cash-for-care models can challenge the already blurred line between paid care work and the unpaid work traditionally performed by women within the household, potentially informalising paid care and support work and reinforcing the gendered undervaluation of this work (Fudge, 2012; Ungerson \& Yeandle, 2007b). In-home work is not highly visible and is difficult to regulate 
effectively, including because employment relations can be highly individualised and conducted within informal relationships (Meagher, 2003).

In this article we examine the planning, design and initial implementation of the NDIS to assess the prospects and risks for disability support workers' pay and conditions in this new cash-for-care scheme. We ask if the scheme is structured in a way that avoids problems that have emerged elsewhere. We draw on policy and program documentation and a small program of interviews with disability service provider CEOs and senior executives, a disability advocate, and senior representatives from employer and industry bodies and trade unions.

We begin with a review of findings of international studies of cash-for-care schemes that address impacts on paid care workers. These studies identify factors that differentiate schemes in relation to their consequences for paid care workers and labour markets, which we use to structure our exploration of prospects and risks for workers under the NDIS.

\section{Cash-for-care: rationales and risks}


Cash-for-care schemes in social care policies

A trend towards the inclusion of cash-for-care schemes in adult social care systems largely reflects a common response to the pressures of meeting increasing care needs as populations age and more women are in the labour force (Colombo et al., 2011). However, such schemes are diverse and reflect different underlying ideas about care and care work (Brennan et al., 2012; Da Roit \& Le Bihan, 2010).

Cash-for-care has its origins in the independent living and disability rights movements of the 1980s and 1990s, which sought new systems of support based on individuals' lifetime goals and strengths (Simon-Rusinowitz \& Hofland, 1993). The objectives of increasing autonomy and empowering care users through enabling them to have greater choice, flexibility and control over services they receive are central to many schemes -reflected in the terms 'consumer-directed' care, 'personalisation' and 'selfdirected support' (Ferguson \& Lavalette, 2014: 27).

Cash-for-care works to 'marketise' care systems as part of broader shifts by governments to adopt market mechanisms to achieve choice, control and efficiency 
through competition (Brennan et al., 2012). This market logic has seen contracting out of publicly-provided services and the entry of for-profit providers in social care markets in many developed countries (Cunningham \& James, 2011). Individual care users are constructed as consumers empowered through the exercise of consumer choice to buy care (Brennan et al., 2012: 378).

Along with increasing independence and choice and developing markets, another common explicit or implicit policy aim of cash-for-care is the recognition of informal carers or the fostering of familial care (Da Roit \& Le Bihan, 2010: 287). A move away from institutionalised care to home-based and informal care provided by family and others is a response to the expressed preferences of care users and often has strong community support (Boxall et al., 2009; Colombo et al., 2010). This move can also be a strategy for containing care costs, often the other driving motivation for the introduction of cash-for care schemes (Ungerson \& Yeandle, 2007a).

Regulation, family and informality in cash-for-care

While cash-for-care schemes can potentially improve care systems, they also produce changes in the labour market and organisation of paid care and support work. Cross- 
national studies suggest three main factors interact to shape better or poorer outcomes for workers: the extent to which cost containment underpins the scheme design; the regulation and monitoring of care delivery; and the regulation of care employment.

Cost containment is particularly important for understanding how cash-for-care schemes might shape care work labour markets and care workers' conditions of work. While there are a number of ways in which schemes support cost containment, all are underpinned by a shift from institutional provision to in-home provision of care. Firstly, home care is cheaper and seen as more effective than care in a residential setting, with the care user remaining largely responsible for accommodation and living costs. Secondly, home care allows greater access to additional unpaid care provided by informal carers - such as family and friends - than the relatively more expensive care provided in an institutional setting. Thirdly, cash-for-care schemes that allow relatives to be 'employed' as carers function to further 'embed' and 'retain' informal care (Ungerson \& Yeandle, 2007b: 189). The argument here is that the schemes act to enlarge the pool of low-cost labour available to provide care. Finally, cash-for-care schemes can shift organisational and employment overheads away from the state and 
onto individual care users. They may also free public agencies from the costs of managing risks to the care user (Ungerson \& Yeandle, 2007b).

The regulation and monitoring of care delivery is the second factor that can vary in cash-for-care schemes and impact on care workers' pay and conditions (Ungerson and Yeandle 2007b). The regulation of care delivery includes care standards and care worker qualifications. The third factor, the regulation of care employment, includes taxation, working hours, conditions, wages, and social protection. Based on their crossnational study, Ungerson and Yeandle (2007b) concluded that a system combining relatively weak regulation of both care delivery and care work, and in which relatives are able to be employed as care workers, is likely to encourage the development of a large low-paid and informal care work labour market.

Similar conclusions are drawn by Da Roit and Le Bihan (2010) based on their European cross-national study of cash-for-care. Quality of care and of care work become issues where consumers have a high degree of choice of worker and there is a lack of external control and monitoring of care labour and outcomes. Further, where previously unwaged informal care work is commodified (i.e. family members are employed as paid carers) boundaries between unpaid and paid work become blurred. This study 
suggests a significant issue is the extent to which some schemes promote the growth of informal, undocumented and unprotected care workforces. The worst outcomes for paid care workers were found to be where long-term care systems are based on poorly-regulated cash-for-care transfers. Such schemes, present in Austria, Italy and Germany, explicitly rely on 'the care, organizational capacity, and monetary contributions provided by families' and implicitly rely on 'an unregulated and lowquality care market' as a partial substitute for this care (Da Roit \& Le Bihan, 2010: 307).

Notably poor outcomes have also been found for care workers under the United Kingdom (UK) direct payments scheme of social care for older people, despite this scheme being 'a relatively regulated policy development which has sought, from the outset, to enable care users to employ their care workers or personal assistants in ways which are consistent with UK employment law' (Yeandle \& Stiell, 2007: 104). Negative impacts in relation to job quality, income security, working time security, health and safety, skill development and representation have been identified under UK direct payments and later personal budgets schemes (Cunningham \& Nickson, 2010; Glendinning, 2012; Hussein, 2011), with the situation apparently worsening following recent austerity cuts (Hussein, 2014). 
The comparative studies of cash-for-care provide some useful parameters and markers for our analysis of likely prospects for disability workers' employment conditions under the NDIS. Specifically, they point to three factors: cost containment - and the role of informal employment in containing costs -; the regulation of care delivery; and the regulation of care employment as significant in shaping outcomes for paid care workers.

\section{Study approach}

To investigate prospects for the direct care and support workforce under the NDIS we first of all analysed policy documents concerned with the planning, design and implementation of the scheme. The NDIS blueprint came out of the Productivity Commission's 18 month long inquiry into the development of a national insurance scheme, undertaken at the Australian Government's request (PC, 2011). We examine the PC's considerations and conclusions relating to the potential impacts of an individualised system on disability care and support workers. 
Our analysis of the NDIS implementation draws on NDIS regulation, operational guidelines, progress reports from NDIS trial sites and on publicly available stakeholder and academic analyses and commentary. We also draw on 12 semi-structured interviews with stakeholders in the disability services sector, including representatives of two national and Victorian not-for-profit (NFP) service providers, a large disability advocacy group, the three trade unions representing direct care and support workers and six Victorian-based NFP disability services providers, five with operations in the Victorian NDIS trial site. All organisations provide services which included personal support and care, accommodation support, respite and community access services to people with physical and cognitive disabilities. The largest organisation had over 500 employees and provided a range of community and welfare services, most had over 100 employees and the smallest had around 50 employees and provided specialist disability services only. All provided home and community-based services, some to aged care clients as well as to people with disabilities.

At the time of our research in 2014 the first NDIS trials had been in place in four states for approximately 12 months, covering a few thousand of the 460,000 or so people who will eventually access support under full implementation, planned for 2019 (Fifield, 2015). In service provider interviews we asked about changes to operations 
and workforce management resulting from the NDIS and for views on any improvements required to meet the workforce demands of the new scheme. From other interviewees we sought views on the design and funding of the NDIS and, in particular, on their experiences of the scheme's impacts on disability workers to date.

Due to the newness of the scheme, and as we have relied on interviews with employers but not employees because organisations were finding their way operating under the NDIS at the time of our fieldwork, our findings can only be suggestive of outcomes in the longer-term. However, our interviews illustrate some of the emerging problems and, combined with evidence from other sources, point to issues which are significant for prospects for both good quality jobs and good quality care and support for people with disability. The research aims to provide an analytical context for further research which would include interviews with disability workers themselves. First, to provide the policy context for our analysis, we outline Australia's disability support system and explain how it changes under the NDIS.

\section{Australia's disability care and support system and workforce and the NDIS}

The disability care and support system and workforce 
Inadequate resourcing of the disability support system has underpinned poor job quality, underemployment and other insecurities for the low-paid care and support workforce in Australia. Service provision has largely been the responsibility of state and territory governments under the Commonwealth State and Territory Disability Agreement (CSTDA) (Australian Government, 2014). Since the 1970s policies of deinstitutionalisation have led to the closure of many, but not all,large governmentrun institutions (MacKinnon \& Coleborne, 2003; Wiesel \& Bigby, 2015). Today the vast majority of disability services are provided by NFP organisations, mainly church-based charitable bodies, and other small service providers. For the most part providers have received block funding in advance to provide services including accommodation support and community access; respite and employment services; and information and advocacy. There has been some individual funding in place under pilot and other arrangements and, in 2006-2007, just over a quarter of disability support packages provided through the CSTDA were individual funding packages (Fisher et al., 2010: 10), mainly in a much more limited form than is possible under the NDIS.

Most disability services providers received $60-80$ per cent of their income from government with the remainder coming from philanthropic contributions, commercial 
activities, investment and other sources (PwC, 2012: 15). Alongside the broader problem of underfunding of services in relation to the needs of people with disability (PC, 2011: 135-390), there has been widespread underfunding of organisations for the provision of contracted services (i.e. funding is inadequate for provision of the services specified in government contracts).

The disability care and support workforce includes managers, health and social professionals, and the non-professional personal carers, home care workers, community care workers, and other support workers. Martin and Healy (2010: 109-21) provide a disability workforce profile of an estimated 68,700 employees, with 73 per cent in the NFP sector, 21 per cent in the public sector and six per cent in the private for-profit sector. Most are direct care and support workers and over 80 per cent are women.

Non-standard employment is the norm for direct support workers, with over 55 per cent employed part-time, and a further 31 per cent employed as casuals - a total of 86 per cent in non-standard employment compared with 50 per cent of the Australian female workforce (Martin \& Healy, 2010: 113). Some work is very short-hours work 
and there is a high level of multiple job-holding, suggesting inadequate hours may be a problem for workers (Martin \& Healy, 2010: 120).

The minimum pay and conditions set out in the Social, Community, Home Care and Disability Services Award (SCHCDS Award) apply to disability workers. The Award specifies somewhat different conditions for disability and other care workers who are employed as 'home care' rather than 'disability support' or other community services workers. For example, casual disability workers who are classified as 'home care' workers have a minimum engagement period of only one hour compared to two hours for workers classified as 'disability support' workers. Further, the pay increases arising from the successful 2012 social and community services equal pay case - which recognised the gendered undervaluation of care work - do not apply to home care workers (Charlesworth, 2012).

What changes with the NDIS?

The NDIS introduces a national system of support for 'people with permanent and significant disability, their families and carers' in place of the variety of disability support and some of the mental health services that have been administered by the 
states (NDIS, 2013). It entails a significant increase in funding for disability support, estimated to be $\$ 8$ billion annually at full implementation, of which 40 per cent of is to come from a Medicare levy increase (Coorey, 2013; Swan, 2013).

A person's support needs are determined by a professional assessment with a subsequent budget allocation made. The person can choose to have the National Disability Insurance Agency (NDIA) manage their funding while they choose their preferred service providers, they can opt to manage their funding and arrange their own supports, or they can appoint a person or organisation to manage their funding and supports (National Disability Insurance Scheme (Plan Management) Rules, 2013).

Under the NDIS eligible people with disability may have access to a much wider range of care and support options than they would have previously and some of the significant benefits are intended to be greater choice and control to determine not only what service is provided but how, when and by whom. For example, before the NDIS a person might attend a specialist day activity service for people with disability. Under the NDIS they may choose to be supported to attend their local gym or swimming pool and participate in 'mainstream' community activities (NDIS, n.d.a). In relation to home-based care and personal support services a person whose personal 
assistance (for example, with showering or dressing) was scheduled by their service provider to fit in with service provision to multiple clients, can now choose a service provider who will provide assistance at their preferred time (NDIS, 2014b).

Alternatively the person may choose to directly employ their own workers. So, while some paid disability workers will remain employed by NFP organisations, others will find employment with for-profit firms that enter the market, and some will be directly employed by or contracted to individuals with disability or their families (PC, 2011).

So, how might these changed arrangements impact on the paid disability workforce? In presenting our research findings, firstly we explore the considerations given to workforce issues and to risks for workers in the planning and design of the NDIS. We examine the Productivity Commission's report of the national inquiry, paying attention to the factors identified in the international literature: the regulation of care employment (and the role of informal employment); the regulation of care delivery; and cost containment. Second, we consider the evidence relating to these factors and to impacts on workers in the implementation of the NDIS, drawing on publicly available documents and our own research interviews. 


\section{The disability care and support workforce in the planning and design of the NDIS}

The Productivity Commission's assessment of risks for the workforce

At the end of an extensive public inquiry the Productivity Commission recommended a publicly-funded system of 'reasonable and necessary' 'individually tailored' supports for people with significant and enduring disability (PC, 2011: 66). Among the Commission's considerations were the likely impacts of self-directed funding on disability workers and the question of individuals employing family members.

The Commission identified a lack of research examining outcomes for the direct care and support workforce in cash-for-care systems. While noting 'the significant body of UK evidence (that) has drawn attention to the potential for lower wages and some other adverse consequences for people employed under self-directed funding', the Commission's Report dismiss much of this evidence, stating 'the results are often ambiguous or likely to be unreliable' (PC, 2011: E25). The Commission point out that studies reporting low wages or inadequate pay: (i) relied on small numbers of respondents (Frontier Economics, 2006; Leece, 2010); (ii) might have (wrongly) assumed the same employer obligations in relation to part-time short-hours 
employees as for full-time employees (Davey et al., 2007); or (iii) might have recorded worker perceptions of low pay and inadequate training that reflected a general perception in the industry (Adams \& Godwin, 2008). However, authors of another review of much the same body of UK-based research reach a quite different conclusion. While also noting the limited evidence base, Cortis et al. (2013), in a report commissioned by the Australian trade unions representing disability workers, conclude the evidence suggests under individualised funding many of the risks associated with increased flexibility are passed from organisations to workers and that the risks associated with contracting and direct employment are substantial. As we noted in our earlier discussion of the international findings, UK research has also identified multiple negative impacts on workers' pay and conditions under direct payments and personal budgets schemes (Cunningham \& Nickson, 2010; Glendinning, 2012; Hussein, 2011, 2014).

The Commission's (2011: 359) conclusion that 'employed support workers generally get better outcomes, though this is not uniform', relies mainly on research findings from the USA relating to workers' subjective feelings of happiness or satisfaction in their jobs. While reliance on such findings can be criticised on the grounds that satisfaction is relative to norms and expectations and reveals little about whether or 
not a system provides quality jobs (Watson, 2005), there are other reasons why the USA-based studies provide an inadequate comparator for the NDIS context.

The Commission reports on the findings of three evaluations of the USA Cash and Counseling program. However, along with positive findings of greater satisfaction and one finding of higher wages (Dale et al., 2005 cited by PC, 2011: E.28), there were also mixed and negative findings including lower wages (PC, 2011: E27), less satisfaction with pay (Benjamin \& Mathias, 2004: 483), and working more unpaid hours (Dale et al., 2004). Further, a significant aspect of the USA program is that most paid workers are relatives of the people with disability who employ them (Foster et al., 2007: 522). Only one study cited by the Commission distinguishes between employed carers who are relatives and those who are not. In this study up to a quarter of the non-relatives knew the person to whom they provided paid care prior to becoming their employees. (Foster et al., 2007), suggesting this program may not be the most appropriate basis for assessing likely impacts on the Australian disability workforce. The Commission also cites a single Australian study as supporting its positive assessment of prospects for disability workers. This is an evaluation of the New South Wales Attendant Care Pilot involving just 10 people receiving self-funded care, in which it is reported only that 
'many of the attendant carers have experienced increased pay and conditions in their new care arrangements' (Fisher \& Campbell-McLean, 2008: 29).

The Commission's Report barely engages with the broader research literature highlighting the vulnerability of workers performing paid care and domestic work in households. The exception is in a discussion of low pay and fragmented work as impediments to recruitment and in recommending the adoption of an immigration program for care and support workers 'in the event of acute and persistent (labour) shortages' (PC, 2011: 720). In pointing to the Canadian Live-In Caregiver Program as a model (PC, 2011: 720), the Commission acknowledged that there had been some abuse of caregivers. The Commission makes no reference to any potential problems with low-paid care workers being in self-employed or independent contracting arrangements.

The Productivity Commission on regulation, family and informality in the NDIS The Commission did not envisage the NDIS would rely heavily on informal work nor include the employment of family members, although this is to be trialled (PC, 2011: 725). However, there is some focus in the Report on the role of informal work as a 
substitute for formal employment and as a means of containing costs. In discussing the legal issues associated with self-directed funding the Commission's focus on employment issues is squarely on employment obligations as a potential barrier to the take-up of self-directed support and on where and how people with disability engaging their own workers might be able to be exempt from such obligations (PC, 2011: F.1F.4). The Report's strong message is that a measure of the success of the NDIS will be the extent to which individuals take up the option of managing funding themselves. While a strong take-up may indicate people with disability are able to exercise choice, the Commission also looks to take-up of self-directed support to keep wages down and to 'partly address anticipated workforce shortages by drawing the so-called "grey" market of family, friends and neighbours into the pool of people who can provide support services' (PC, 2011: E.24).

The Commission thus appears to anticipate and sanction some informalisation of paid direct care and support work, while paying little attention to potential negative outcomes for workers. For example, the possibility of direct care and support workers being engaged as independent contractors is considered in a discussion of how people with disability might be able to minimise employment obligations (PC, 2011: F.2). Elsewhere it is suggested that '(i)n many instances, self-directed funding would involve 
no superannuation, tax withholding or OH\&S obligations' (PC, 2011: 379). Among the examples of such instances - along with a neighbour sometimes driving a person to a gym class or mowing their lawn and an adolescent babysitting a child with disability - the Productivity Commission includes:

'a support worker (who) provides an average of 10 hours of care a week in the home of the person with a disability, but with the amount of work and the times when it takes place varying with the needs of the person with a disability'. (PC, 2011: 140).

Prior to the NDIS a paid care worker providing home care, as in this example, would typically be employed under the SCHCDS award and would not have to take on the responsibilities, risks and costs normally associated with self-employment. The Commission's only recommendations regarding the regulation of care work to reduce risks to workers in self-directed support arrangements were that workers should be covered by workers' compensation and have an avenue to make complaints (PC, 2011: 75). 
In relation to the regulation of care delivery the Commission proposed some oversight by care coordinators, along with easy access to police checks on workers and capacity for people with disability to have complaints of inappropriate behaviour by service providers investigated (PC, 2011: 74-75). The Commission recommended against a qualifications requirement or compulsory training for direct care and support workers (PC, 2011: 693). This is despite the fact that almost 80 per cent of the current workforce has some form of training, mostly either a Certificate III or IV (Martin \& Healy, 2009: 126-27).

The NDIS has proceeded largely in keeping with the Commission's vision and recommendations. As we outline below, there are no particular safeguards built into the new system addressing work quality and there is some early evidence of pressures eroding working conditions. In addition we find that the light touch regulation of care delivery and a focus on containing costs may also work to undermine care workers' pay and working conditions.

\section{Implementation of the NDIS}


Containing costs in a competitive market

Additional government funding under the NDIS will expand service provision to provide much-needed supports to people who have previously not had - or have had inadequate - services and supports (PC, 2011). However, the advent of the NDIS does not mean particular care and support services will be better-funded. Indeed, existing service providers face major financial challenges under the NDIS pricing structure as they make the transition to the competitive system (Green \& Mears, 2014). A key issue for many providers may be lack of organisational capacity to participate successfully, not only because of their small size, but because of the legacy of government underfunding (PC, 2010: 281). Despite assurances from the NDIA that service providers will be supported to make the transition to the new system (NDIS, n.d.b), the viability of small providers in particular remains in doubt (Lannen, 2014). With funding allocated to individuals, providers face much less certain and potentially reduced income (National Disability Services [NDS], 2013). Reduced ability to provide security of employment to what is already a highly casualised and part-time workforce may well be one consequence, as suggested by service providers in our interviews, discussed below. 
Under-funding of services continues under the NDIS. In particular the prices set by the Commonwealth for the highest volume supports of 'one-to-one assistance with selfcare activities' and 'assistance to access the community' are considered by NDS, the main body representing NFP service providers, to be too low, even after a review and price increase in 2014 (NDIS \& NDS, 2014: i). Both of these types of supports are provided by the low-paid non-professional direct care and support workforce. An additional problem is that prices are set at one level despite the range of levels of complexity of care required. CEOs and senior managers in large and small organisations told us they could not afford to provide direct care and support services with the level of funding they received under the NDIS. As outlined in the discussion below providers found the pricing structure did not adequately account for the costs of supervision, professional development and training or administration. Indeed some argued the price was too low to enable them to employ direct support and care workers in compliance with the SCHCDS award. The comments of this CEO of one large organisation are typical of service providers we interviewed:

We're rock solid around the principles (of individualisation) and we, most of the disability sector, would be behind (worker) qualifications and decent pay but it's not possible to deliver (personal care) with qualified supported staff at these prices. (Vicprovider1) 
Regulating for quality care?

An initial assessment suggests a combination of minimal regulation, more variable patterns of demand and tighter funding is placing pressure on service quality under the NDIS in the trial sites. To date, the regulation of care provision under the NDIS appears relatively light touch. A provider of support and care must be registered with the NDIA only if a person with disability has their funding and support managed by the NDIA. However, if a person manages their own funding the NDIS places no restrictions on who can provide services. This is also the case where a person's funding is managed by a third party 'plan management provider' although this provider must be registered (NDIS [Registered Providers of Supports] Rules, 2013). While the criteria for registration include considerations of the provider's relevant experience and qualifications, for care and support workers there are no qualifications requirements (NDIS, 2013). A quality and safeguards framework is still to be implemented but it is not anticipated that this will include any qualifications requirements for these workers (NDIS, 2015) 
The five NFP disability service providers interviewed in the Victorian NDIS trial site were attempting to deal with significant immediate changes under the new arrangements while also trying to anticipate and plan for the full implementation of the new market. Some providers reported they had responded to increases in demand at peak times by recruiting, as the regional manager of one large service provider organisation put it, 'anyone standing'. The same manager said 'we are losing staff to other industries ... Some have gone to aged care facilities, the pay is lower but they're going for the security' (Trial site provider 3). This manager, along with three others in organisations of different sizes, all anticipated they would need larger 'more flexible' workforces to provide the same level (but more diverse) services under the NDIS. For example, another executive manager of an organisation providing home-based services told us:

(t)here have already been lots of one hour shifts, lots of travel time. We've got staff working 15 hours to get 8 hours' pay, and they're running their own vehicles. ... We try and have shifts backing on to each other but it's not always do-able' (Trial site provider 4).

Service providers we spoke to said the NDIS required better-trained and supported workers and good processes for monitoring care and support provision, particularly as 
this was more likely to be in diverse settings including in people's homes. However, the low level of pricing of direct care and support work and lack of certainty of demand in the NDIS competitive market, made it difficult to recruit and retain workers and to provide the same level of training and supervision as prior to the NDIS, as described by this senior manager:

One of the biggest problems is (we get) the same low rate (of funding) even for complex clients; we get paid the same as for any other client. There's not much money left over to develop a workforce. In the longer-term we just won't have the skills. ... Values are important, it's not just training, but the Certificate's important too. (Trial site provider 1)

Employment regulation and impacts on care workers

Under the NDIS there is greater diversity - and also often less predictability - in the type, timing, and settings in which disability care and support is provided. Many of the immediate challenges to providing jobs with decent pay, predictable hours, and job security for direct care and support workers arise from this increased diversity and unpredictability. 
Several providers - large and small - reported increased reliance on casual staff, including as a strategy to manage more frequent roster changes which require notice time or consultation when involving permanent staff. Increased use of casual staff was also a response to difficulties providers experienced in giving employees certainty of total weekly work hours and of start and finish times, also requirements for permanent employees under the SCHCDS award. One union representative reported some organisations were classifying employees as home care workers where previously they would have been classified as disability support workers. The apparent reason for this was the reduced minimum period of engagement for home care workers under the award compared to other employees.

These accounts from early experiences in the Victorian NDIS trial site resonate with provider experiences reported by the peak NFP provider body, the NDS, from their consultations across all the NDIS trial sites. Among the workforce implications identified by the NDS are 'increasing back office (work), more casuals employed, different types of workers employed, disputed relevance of formal qualifications, increased demands of staff, less ability to offer training and professional development, weaker supervision (and) increasing workplace health and safety risks' (NDS, 2014: 1). 
Some service providers interviewed called for greater 'flexibility' through changes to the SCHCDS award and also for the abandonment of existing enterprise agreements, which provided some above-award conditions, such as travel time. These calls are illustrated by comments from two trial site service providers:

The existing sector awards just don't match the flexibility the clients want ... There was pressure to pay staff for two hours and that's in our new (enterprise) agreement. However (the agreement) hasn't gone through yet so we're still able to have one hour shifts at the moment which is what we need. Unless awards are more flexible and funding increases we won't be able to do it. (Trial site provider 5)

The ideal would be to be a new player in the market and not to have the millstone of the current workforce and their conditions round our neck. (Trial site provider 2)

Two providers named reductions or abolition of penalty rates for work in unsocial hours, the reduction of minimum engagement and notice periods and the ability to average agreed work hours over longer periods as changes needed. One suggested the 'the award safety net is way too high' (Trial site provider 2). These claims are similar to 
those made by disability services employers in the Modern Award Review process (Jobs Australia, 2015; NDS, 2015). They echo calls of 'key informants' reported by the NDS suggesting a 'non-bargaining forum' for industrial relations parties and participants to find solutions to issues including 'minimum shift lengths; notice of changes to shifts; a new classification structure; flexible deployment of staff across job roles; travel and broken shift allowances; and penalty rates and the span of normal hours' (NDS, 2014: 8). Indeed, such interest-based negotiations outside the Fair Work Commission's formal review process have been taking place (Morton 2014).

Some of the most immediate concerns of the CEOs and managers interviewed were with the challenges of providing services in compliance with award conditions and with how greater flexibility might be gained through changes to industrial arrangements. However, several also raised concerns about operating in a market in which firstly, they have obligations as employers that do not apply to others (e.g. in situations of direct employment or contracting of workers); and secondly, in which it appears some providers and service users are not complying with employment regulation. To illustrate, one CEO said his organisation had not proceeded with a proposed partnership with a labour hire agency as the agency employed disability support 
workers under less favourable attendant care award conditions (Trial site provider 1 ), with similar concerns raised by providers consulted by the NDS (2014).

Service providers, a union interviewee and a disability advocate reported that people with disability and some provider organisations were engaging direct care and support workers as independent contractors, sometimes with pay and conditions that undercut the award or did not comply with occupational health and safety or other regulatory requirements. They also reported that engagement of workers as independent contractors was not uncommon under an existing Victorian individualised support scheme, although there is no reliable data on the proportion of that workforce who work as independent contractors. An issue here may be the limitations and weakness of the regulation of independent contracting. While sham contracting is illegal under federal employment regulation, the invisibility of work performed in the home and the complexity of determining the legality or otherwise of any contracting arrangement make it very hard to ensure that workers are not coerced into independent contractor arrangements (Roles \& Stewart, 2012). Further, this legislation does little to protect low-paid contractors from the high levels of risk and insecurity associated with this work arrangement (Johnstone et al., 2012). 
Other gaps in employment regulation may be exploited as illustrated by an example provided in a direct employment guide for people with a disability (My Place, 2013). Where a person manages their own funds and directly employs or engages a worker to provide personal or domestic support in their home for 30 or fewer hours a week there is no superannuation guarantee payment made for the worker under an exemption for people employed by a householder 'to do work wholly or principally of a domestic or private nature for not more than 30 hours per week' (ATO Superannuation Guarantee Ruling SGR 2005/1). As suggested in the employment guide, a person with disability can structure their care and support so that it is provided by multiple parttime workers rather than a single worker so that these exemptions apply (My Place, 2013). Notably the NDIA does not discourage individuals and their families from engaging care and support workers as independent contractors. Indeed, the NDIS information on employing support workers states workers 'can generally be engaged as employees or as independent contractors' (NDIS, 2014a). The NDIA has no oversight of service provision contracts where people manage their own funds.

\section{Concluding comments}


The NDIS is an important development with the potential to bring significant improvements for people with disability. This potential is unlikely to be realised in the long term if the implementation of the NDIS model of individualised care weakens the sustainability of the workforce by undermining what are already fairly basic labour minima in disability support jobs.

As with cash-for-care systems elsewhere, the NDIS carries risks for both the quality of care jobs and the quality of support and care provided. Our preliminary analysis has shown the factors implicated in poor outcomes for care workers in other countries are present to some extent in the design and trial implementation of the NDIS. There is evidence of cost containment, including through some reliance on informal work, and there are gaps in the regulation of care quality and care employment.

Cost containment may not be as explicit a policy goal under the NDIS as it is in other countries' cash-for-care schemes. However, both the lack of attention to the impact of a new funding model on employment conditions in the design of the NDIS and some encouragement by agencies responsible for its implementation for people with disability to 'work around' existing employment conditions suggest the quality of disability service employment may be compromised. Further, the light-touch 
regulation of the quality of care delivery, particularly where individuals are direct employers, and pressures to weaken the formal but basic minima in the SCHCDS award may work to undermine the viability of the NDIS over the long term.

In our view, evaluations of the pilot implementation of the NDIS at the trial sites need to focus directly on the impact on and implications for current and future disability support workers and address the strong links between the quality of jobs in the sector and the quality of services provided. Recent collaborations between disability advocacy groups and unions in North America suggest there may be innovative ways to meet the needs of people with disability for autonomy and control as well as the needs of workers for job security, predictable scheduling and sufficient hours (Cranford, 2015).

Notes

\section{References}


Adams L and Godwin L (2008) Employment Aspects and Workforce Implications of Direct Payments. Prepared for Skills for Care, London: IFF Research.

Australian Government (2014) ‘Commonwealth State Territory Disability Agreement Factsheet'. Canberra: Department of Social Services.

Benjamin A and Matthias R (2004) Work-life differences and outcomes for agency and consumer-directed home-care workers. The Gerontologist 44 (4): 479-88.

Boxall K, Dowson S, \& Beresford P (2009) Selling individual budgets, choice and control: local and global influences on UK social policy for people with learning difficulties. Policy \& Politics 37: 499-515.

Brennan D, Cass B, Himmelweit S, Szebehely M (2012) The marketisation of care: Rationales and consequences in Nordic and liberal care regimes. Journal of European Social Policy 22(4): 377-391. 
Charlesworth S (2012) Decent working conditions for care workers? The intersections of employment regulation, the funding market and gender norms. Australian Journal of Labour Law 25 (2): 107-132.

Christensen K, (2012) Towards sustainable hybrid relationships in cash-for-care systems. Disability \& Society 27 (3): 399-412.

Colombo F, Llena-Nozal A, Mercier J \& Tjadens F (2011) Help Wanted? Providing and Paying for Long-Term Care, OECD Publishing. http://dx.doi.org/10.1787/9789264097759-en Paris: OECD.

Commonwealth of Australia (2013) 'DisabilityCare Australia: Stronger, Smarter, Fairer'. Available at http://www.budget.gov.au/201314/content/glossy/ndis_policy/download/ndis.pdf (accessed 8 October 2014). Coorey P (2013) 'Medicare rise to fund disability scheme' Australian Financial Review, 30 April. Available from http://www.afr.com/news/politics/national/medicare-rise-tofund-disability-scheme-20130501-j0vbw (accessed 1 September 2014). 
Cortis N, Meagher G, Chan S, Davidson, B and Fattore, T (2013) 'Building an industry of choice: Service quality, workforce capacity and consumer-centred funding in disability care', SPRC Report 02/13, Sydney: Social Policy Research Centre, University of New South Wales.

Cranford, C (2015) 'Toward particularism with security immigration race and the organization of personal support services in Los Angeles' in B Anderson and I Shutes (eds) Migration and Care Labour: Theory, Policy and Politics, Palgrave Macmillian, Basingstoke.

Cunningham I and James P (eds) (2011) Voluntary Organizations and Public Service Delivery. New York: Routledge.

Cunningham I and Nickson D (2010) Personalisation and its Implications for Work and Employment in the Voluntary Sector. Glasgow: University of Strathclyde.

Dale S (2005) How do hired workers fare under consumer-directed personal care? The Gerontologist 45 (5): 583-92. 
Dale S, Brown R, Phillips B, Schore J and Carlson B (2004) The Effect of Consumer Direction on Personal Assistance Received in Arkansas, Final Report (revised May 2004), Princeton, NJ: Mathematica Policy Research Inc.

Da Roit B and Le Bihan B (2010) Similar and yet so different: Cash-for-Care in six European countries' long-term care policies. Millbank Quarterly 88 (3): 206-39.

Davey V, Fernández J, Knapp M, Vick N, Jolly D, Swift P, Tobin R, Kendall J, Ferrie J, Pearson C, Mercer G, and Priestley M (2007) Direct Payments: A National Survey of Direct Payments Policy and Practice Participating Organisations, 2007, London: London School of Economics and Political Science.

Ferguson I and Lavalette M (2014) The crisis in adult social care in I Ferguson and M Lavalette (eds) Adult Social Care, Bristol: Policy Press, 1-36.

Fifield, M (2015) 'NDIS now supporting over 10,000 people with disability', Joint Media Release, 5 February. Available from http://mitchfifield.dss.gov.au/media-releases/ndisnow-supporting-over-10000-people-with-disability (accessed 19 February 2015). 
Fisher KR and Campbell-McLean C (2008) Attendant Care Program Direct Funding Pilot Evaluation, Final Report, SPRC Report 11/08. Report prepared for the NSW Department of Ageing, Disability and Home Care. Sydney: University of New South Wales.

Fisher KR, Gleeson R, Edwards R, Purcal C, Sitek T, Dinning B, Laragy C, D'aegher L and Thompson D (2010) 'Effectiveness of individual funding approaches for disability support'. SPRC Occasional Paper no. 29. Australian Government Department of Families, Housing Community Services and Indigenous Affairs (FaHCSIA). Canberra: FaHCSIA.

Foster, L Dale, SB and Brown R how caregivers and workers fared in Cash and Counseling. Health Services Research 42: 510-32.

Frontier Economics (2006) Choice in the Delivery of Local Government Services: A report prepared for the Audit Commission, London: Frontier Economics Ltd. 
Fudge J (2012) 'Blurring legal boundaries: regulating for decent work' in J Fudge, S McCrystal \& K Sankaran (eds) Challenging the Legal Boundaries of Work Regulation. Hart Publishing, Oxford: 1-26.

Glendinning C (2012) Home care in England: markets in the context of under-funding, Health and Social Care in the Community, 20 (3), 292-99.

Green J and Mears J (2014) The implementation of the NDIS: Who wins, who loses? Cosmopolitan Civil Societies Journal 6(2): 3915.

Hussein S (2011) Estimating probabilities and numbers of direct care workers paid under the national minimum wage in the UK: A Bayesian Approach, Social Care Workforce Periodical, issue 16, December.

Hussein S (2014) 'Evidence and Reflections for The Kingsmill review of exploitation in the care sector', Submission to the First Roundtable on Working Conditions in the Care Sector, 20 February, Social Care WorkForce Research Unit, King's College London. 
Jobs Australia (2015) '4 yearly review of Modern Awards: Outline of issues and proposed variations Group 3 AM2014/232 \& Group 4 AM2014/285', Submission to Fair Work Commission, 2 March. Available from https://www.fwc.gov.au/awards-andagreements/modern-award-reviews (accessed 13 March 2015).

Johnstone R, McCrystal S, Nossar I, Quinlan M, Rawling M \& Riley J. (2012) Beyond Employment: The Legal Regulation of Work Relationships. Sydney: The Federation Press, Sydney.

King D and Meagher G (eds) (2009) Paid care in Australia: Politics, Profits, Practices. Sydney: Sydney University Press.

Lannen D (2014) Local providers can't run on NDIS rations. Geelong Advertiser, 16 December.

Leece J (2010) Paying the piper and calling the tune: Power and the direct payment relationship, British Journal of Social Work, 40: 188-206. 
MacKinnon D and Coleborne C (2003) Deinstitutionalisation in Australia and New Zealand, Health and History, 5(2): 1-16.

Martin B and Healy J (2010) Who works in community services? A profile of Australian workforces in child protection, juvenile justice, disability services and general community services. Adelaide: National Institute of Labour Studies.

Morton, R (2014) 'Secret Fair Work talks on NDIS “workplace' reform"' The Australian, 1 December 2014.

My Place (2013) A guide to engaging your own support workers. Perth: My Place Ltd. Available from http://www.ndis.gov.au/document/450 (accessed 24 December 2014). NDIS (2013) Quality assurance and safeguards working arrangements for the launch of the NDIS in Victoria as agreed between the Commonwealth of Australia and Victoria, as at May 2013. Geelong: NDIS.

NDIS (2014a) Employing a support worker: Laws and obligations, information for participants on engaging their own support worker. Geelong: NDIS. 
NDIS 2014b 'Managing your participant plan' NDIS Factsheet. Geelong: NDIS.

NDIS (2015) ‘Proposal for a National Disability Insurance Scheme quality and safeguarding framework.' Consultation paper. Available from https://engage.dss.gov.au/ndis-qsf/ (accessed 22 April 2015).

NDIS (n.d.a) 'Examples of services and support', NDIS Website. Available from http://www.ndis.gov.au/people-disability/examples-services-and-support (accessed 12 April 2015)

NDIS (n.d.b) 'Not for profit disability service providers' NDIS Website. Available from http://www.ndis.gov.au/community/not-profit-disability-service-providers (accessed 12 April 2015)

NDIS and NDS (2014) Final Report of Pricing Joint Working Group, Geelong: NDIS. 
National Disability Services (NDS) (2013) NDS Submission to the Council of Australian Government's consultation: National Disability Insurance Scheme Regulatory Impact Statement, Deakin: NDS.

National Disability Services (NDS) (2014) Forming a national disability workforce strategy. National Disability Services (NDS) Discussion paper.Deakin: NDS.

Netten A, Jones K, Knapp M, Fernandez J L, Challis D, Glendinning C, Jacobs S, Manthorpe J, Moran N, Stevens M and Wilberforce M (2012) Personalisation through Individual Budgets: Does it work and for whom? British Journal of Social Work 42: 1556-1573.

Organisation for Economic Cooperation and Development (OECD) (2011) Help Wanted? Providing and Paying for Long-Term Care. Paris: OECD.

Productivity Commission (2010) Contribution of the not-for-profit sector. Research report, Canberra: Productivity Commission. 
Productivity Commission (2011) Disability care and support: Productivity Commission Inquiry Report, volumes 1 \& 2. Report no. 54. Melbourne: Productivity Commission.

PwC (2012) Planning for a sustainable disability sector. Canberra: FaCHSIA.

Roles C \& Stewart A (2012) The reach of labour regulation: Tackling sham contracting, Australian Journal of Labour Law, 25: 258-83.

Simon-Rusinowitz L and Hofland B F (1993) Adopting a disability approach to home care services for older adults. The Gerontologist 33:159-67.

Swan, W (2013) 'Locking in a fairer future for Australians with disability' Joint Media Release with the Hon Julia Gillard MP Prime Minister and the Hon Jenny Macklin MP Minister for Disability Reform, 1 May 2013. Available from http://ministers.treasury.gov.au/DisplayDocs.aspx?doc=pressreleases/2013/057.htm\& pagelD $=003 \& \min =w m s \& Y e a r=2013 \&$ DocType $=0$ (viewed 18 April 2015).

Ungerson C (1997) Social politics and the commodification of care. Social Politics 4 (3): $362-81$. 
Ungerson C and Yeandle S (eds) (2007a) Cash for Care in Developed Welfare States. Houndsmills, Basingstoke: Palgrave Macmillan.

Ungerson C and Yeandle S (2007b) Conclusions: Dilemmas, contradictions and change, in C Ungerson and S Yeandle (eds.) Cash for Care in Developed Welfare States. Houndsmills Basingstoke: Palgrave Macmillan, 187-206.

Watson, I (2005) Contented workers in inferior jobs? re-assessing casual employment in Australia, Journal of Industrial Relations, 47: 371-92.

Wiesel I \& Bigby C (2015) Movement on shifting sands: Deinstitutionalisation and people with intellectual disability in Australia, 1974-2014, Urban Policy and Research, DOI: $10.1080 / 08111146.2014 .980902$.

Yeandle S \& Stiell B (2007) 'Issues in the development of the Direct Payments Scheme for older people in England' in C Ungerson, \& S Yeandle (eds) Cash for Care in Developed Welfare States, Palgrave Macmillan, Houndsmills Basingstoke: 104-36. 